\title{
Happiness and its Relationship to Psychosocial Adjustment among Teenagers in the Protection and Care Houses in Amman
}

\section{Dr. Abdallah Salem Farhan Almahaireh}

Associate Professor,University of Jordan,School of Education Science,Department of Counseling and Special Education Amman - Jordan,Email: a.mahaere@ju.edu.jo

\section{Rania Ali Ismail Omar}

Master's degree in psychological and educational counseling,Social worker, Ministry of Social Development Amman - Jordan,Email: rania_Omare@yahoo.com

This manuscript has not been published elsewhere and is not under consideration for publication elsewhere. The data that support the findings of this study are available from the corresponding author, [Dr. Abdallah Almahaireh], upon reasonable request.

This manuscript did not receive any funding.

No potential competing interest was reported by the authors.

\section{ABSTRACT}

This study aimed to reveal the level of happiness and psychosocial Adjustment among teenagers living in protection and care houses in Amman, to know the possible relationships between these factors and the possible differences according to brothers exist and age. By using a quantitative approach, 82 Teenager were selected from the teenagers their ages are between (12-16) years, to achieve the objectives of the study, the study measures were developed and the indications of validity and reliability of the two scales were verified and applied to the study sample. Their levels of happiness and psychosocial Adjustment were found to be moderate, with a statistically significant positive correlation between the variables. Also, the results revealed a statistically significant difference in the level of both happiness and psychosocial Adjustment according to brothers exist in favor to who has brothers and according to age in favor of less than 15 years.

Keywords:

Happiness, Psychosocial Adjustment, Teenager, Protection and Care Houses.

Article Received: 18 October 2020, Revised: 3 November 2020, Accepted: 24 December 2020

\section{Introduction}

The happiness and Psychosocial Adjustment of teenagers in protection and care houses are important and the workers in psychology and counseling focus on because of their impact on the personal dimensions of the teenager and the extent they had mental health, also it measures the extent of Adjustment to the new circumstances, and his independence and harmony with the members of the society he lives in, this psychological and social harmony improves the extent of his satisfaction about himself and his society and his sense of happiness.

Adolescence is a sensitive period due to the various physical, emotional, and social changes it entails, and this period is also characterized by the developmental needs related to Psychosocial Adjustment and happiness, all of which require him to adapt properly with it, and to enjoy independence and form social relationships with peers of both gender (Speier, et al., 2015).

The teenager is a part of society and has an important role in building and developing it, and his behaviors that are contrary to the society culture are the results of his attempt to express himself to draw attention to those around him, being in a stage where he finds it difficult to express himself, sharing his feelings with others and satisfying his needs, according to the various requirements of growth, as well as showing increased sensitivity to others in the cases that they do not understand him, so it is necessary for those around him and those who care for him and raise him to understand his feelings during this stage, the psychological fluctuations facing him, 
and caring for him to work to transfer him to the youth stage wisely (Herbert, 2016) .

Happiness is one of the concepts that have been addressed in the fields of psychology, and it has had a great impact on positive psychology, that is the science that searches for the positive dimensions of a person and strengthens them. Happiness is a positive mood that expresses the extent of an individual's satisfaction with his life, the extent of his optimism about the future and his ability to achieve himself. It is a relative emotional state differs from one individual to another, where the difference is due to several factors that are determined by the individual himself, such as health, economic status, psychological state, and social status (Al-Sawafi, 2019).

A teenager can be considered happy when he has a positive outlook towards himself, and he can find positive methods to enjoy his life moments, and he can set goals that he seeks to achieve optimism about the future, and he has the ability to interact with others during his integration with different social situations, in addition to his feeling of comfort, harmony and satisfaction in the place where he lives In It (White, 2013).

According to recent studies as a study of Mohammadzadeh, Awang, Kadir \& Ismail (2018) which indicate the importance of studying risk factors on teenagers that negatively affect their mental health and expose them to psychological problems such as anxiety, depression, and instability, which negatively affect their level of Psychosocial Adjustment and Self appreciation.

but Amalu (2017) study showed the effect of socialization methods and the environment in which a teenager lives on his Psychosocial Adjustment, as the environment in which tension, conflicts and emotional deprivation cause a poor Psychosocial Adjustment, while the social environment that gives the respect and confidence and gains the appropriate skills that help him overcome difficulties and improve the level of Psychosocial Adjustment.
Some studies (Kazem, 2017; Gusniarti, Rahaju, English, Dewi \& 2017; Pour, Yazdkhast, Oreyzi \& Chitsaz2018) indicate that there is a positive correlation between happiness and psychosocial adjustment, so the positive dimensions of happiness work to enhance the personality traits of the teenager and give him the ability to employ his abilities and skills in building positive social relationships and interacting with members of his community, so teenagers who were able to satisfy their needs and desires properly feel comfortable and happy with the surroundings, because they were able to overcome the difficulties they faced, happiness does not mean that the teenager did not go through challenges, but rather how he overcame these challenges

\section{Research Problem}

This study based on the happiness of Psychosocial Adjustment among teenagers in the protection and care houses in Amman, and to clarify the relationship between the happiness and psychosocial Adjustment according to brothers exist and age variables , after reviewing previous studies related to the subject, and noting the need to conduct studies that address the variables of the current study on teenagers residing in protection and care houses, as psychosocial adjustment is an important and influential factor in the formation of the individual's personality, self-esteem and happiness. And the ability to the investment what he receives from the services within protection and care houses to improve his Psychosocial Adjustment and to feel comfortable and happy, therefore the problem of the study was to answer the following questions:

1. What is the level of happiness among teenagers in protection and care houses in Amman?

2. What is level of psychosocial adjustment among teenagers in the protection and care houses in Amman?

3 . Is there a statistically significant relationship at the level of significance $(\alpha=0.05)$ between 
happiness and the psychological adjustment in the protection and care houses in Amman?

4. Are there differences in the level of psychosocial adjustment and happiness due to brotherhood exist among teenagers in protection and care houses?

5. Are there differences in the level of psychosocial adjustment and happiness due to the age (less than 15) (more than 15) among teenagers in protection and care houses?

\section{Literature Review}

Adolescence is one of the critical developmental stages in which a person develops from childhood to adulthood, and this stage is characterized by the occurrence of many biological changes: in body shape, height, weight, and maturity of the sexual organs, and psychological changes: as in the expression of feelings and emotional and social instability: as in how to build relationships with peers, changes are varied and accelerating (William, Holmbeck, \& Greenley, 2002). This longer phase is the most challenging phases during the life of an individual because of the occurrence of many problems between the teenager males and females with their families or who cared about them because they have tantrums, excessive sensitivity to simple attitudes, refusing to obey the community standards (Melgosa, 2010).

during the phase of the developing between childhood and adulthood, the teenager struggle himself between relying on his family or depending on himself, due to the various changes that occur from the mental and physical, emotional maturity and social, such as the rapid body growth accompanied by biological and physiological changes, in addition to the mental capacity growth, and passing emotional and social experience which contribute to form his attitudes and beliefs and values (shopr, 2017) .

The researchers of the humanitarian aspects have a great interest to study four aspects of developmental teenager they are :temporal aspect, biological aspect, psychological aspect and social aspect as they have a role in achieving happiness psychological and social adjustment ,temporal aspect is the time where the individual develops in age experiences from childhood to youth, which ranges from eleven to twenty-two years old, and the biological aspect is the physiological changes that occur in the individual's body in length, weight and maturity of the organs, but the psychological aspect is the behavioral changes indicative of the harmonious and adaptive behavior of the individual and the extent of his compliance with the values and culture of society. Finally, the social aspect, which is the stage of reliability to build social relationships with others, (Khalada and Alozkaa, 2012).

\section{The protection and care houses}

The Hashemite Kingdom of Jordan is concerned with teenagers residing in protection and care houses since 1953 in implementation of the Royal Visions, which emphasized the responsibility of the State towards children and teenagers because they are part of human wealth and confirmed that late, King Hussein Bin Talal said : "people are our most valuable assets ."so a great attention to vulnerable groups without family bonds (orphans, family disintegration, unknown parentage, unknown parentage with known mother, risk neglect, victims of domestic violence) continued in the protection and care houses since the establishment of the Hussein Social Foundation, which is the first institution concerned with protection and care. This was followed by the opening of the Dar Al Barr for innocent buds, and the strengthening role of the private sector and providing support to the voluntary associations that take care of these groups, under high supervision by the Ministry of Social Development (the Ministry of Social Development,2019).

As the interest in teenagers residing in protection and care houses increases, because they are sensitive groups that have suffered from emotional deprivation and a lack of security and stability, which leads to facing psychological pressures that may affect the continuity of pursuing their life affairs in a balanced manner; Especially if they are unable to find someone to 
provide them with the appropriate support to satisfy their psychological and social needs, and to help them overcome these pressures and get along with the new situation (Khoj,2014).

a lot of teenagers suffer from the pressures of the emotional deprivation of the normal family and expose them to problems of integration with society represented by ostracism and rejection to them and putting them in the negative template that deprives them of harmony in society and feeling happy, here becomes the role of psychological and social support services in the protection and care houses is to improve their level of Psychosocial Adjustment and their sense of comfort And happiness, by working to provide an appropriate environment for the growth of the teenager, in a safe family environment in which he enjoys good physical and mental health, to become socially and emotionally qualified and able to interact with society, after it is impossible for him to live in the care of any of his original family members, or any Suitable alternative family (Atwood \& Schooler, 2014) .

\section{Happiness}

The concept of happiness is one of the concepts that belongs to positive psychology where Seligman used the two words of happiness and kindness as synonyms to describe the goals of the positive psychology project and he include positive emotions and positive activities (Friedma \& Wyatt, 2008), happiness is the goal of humanity which they are seeking to achieve it and it's a product of what have been achieved in humans when it has filled the needs and desires in a suitable way with the social environment in which they live, that's why happiness is associated with accomplishment . happy People are performing better, through the positive sense, life satisfaction, and stay away from negativity (Bazrafshan, et al. 2018).

The concept of happiness is relative, as it happiness sources differs according to the interests and needs of each individual, Seligman noted that social relations are one of the most important sources of happiness, such as companionship , friendship , marriage and neighborhood, and it can reduces the fuss in humans and increases health, and increase the mental health development ,but on the professional side, unemployment may cause unhappiness, and good work is one of the causes of happiness for a person, and there are some people tend to be happy, and others tend to be unhappy because of their different personality type, and he added that religion is one of the most important sources of happiness, and that health is related to happiness and the feeling of contentment as they are the result of happiness ( Zahra ,2017).

\section{Psychosocial adjustment}

The psychological adjustment is the way in which the individual saturates his motives, as life is a set of Adjustment processes in which the individual modifies his behavior to respond to the renewed requirements and needs, so the Adjustment is closely related to the physical and sensory dimensions of the organism, while the concept of adjustment is related to the psychological and social dimensions, that is what the person distinguishes himself to organize his life, and confront his problems and try to solve them (Beck, 2008). As Sunil (Snell, 2000) Believes that the psychological adjustment of the teenager produced through positive interaction between him and the surrounding environment and his ability to continue accordance to his skills in consistent with the circumstances surrounding it.

As the social adjustment of the teenager, which results through his interaction with others, and his commitment to the ethics and the conduct of the society according to the rules and standards of society, the acceptance of social change, proper interaction with individuals, bearing social responsibility, and working with the group (Zahran, 2002), social Adjustment is how the teenager understand his abilities and social skills and how to employ them in the composition of successful social relationships with others inside and outside the environment surrounding him with 
his commitment to ethics and values of the community and the participation of social events and interaction with others (Dewi \& Agustin \& Satwika, 2017).

Psychosocial Adjustment is defined as the teenager's ability to respond appropriately to the situations and pressures he is exposed to in the surrounding environment, and this indicates the extent of his ability to meet internal requirements (Rizvi, 2016), Which it is a continuous dynamic process between the individual and himself, by finding positive methods and skills that achieve a comfort and harmony with the environment, and also through building social relationships with the surrounding individuals in various social situations (Potrus ,2008)

as a result, psychosocial adjustment includes three social levels they are: first psychological dimension is when the individual saturates his needs and psychosocial motives, the second social dimension is when the individual satisfies his needs within the standards set by the society in which they live, and the third dimension is the complementary between social and psychological dimensions as an interaction and integration between the psychological and social dimension. Psychological accommodation is seen as a two-sided process that includes the individual's belonging to the social environment in general and the society in which he lives (Alsead,2014).

Many studies have concentrated on happiness and psychological and social harmony, as Moshe study (Lmoshi, 2019) aimed to reveal the level of Psychosocial Adjustment of working children, and the extent of the difference of gender $\mathrm{s}$ in the level of Psychosocial Adjustment of working children in the streets of the city of Blida in the State of Algeria, and the results of the study found a decrease in the level of Psychosocial Adjustment among working children, and there is presence of statistically significant differences in the level of psychosocial harmony is attributed to the favor for males.

Study of (Shawaqfeh \& Almahaireh , 2019) aimed to reveal the level of both technological wellness and happiness and optimism among undergraduate students at the University of Jordan, the study results showed that students happiness level was "moderate", and a lack of statistically significant differences due to gender in the level of happiness, also a study of ( Shammari , 2017) aimed to study how we can predict happiness through psychological security among teenagers orphans in care and ordinary centers, and the results of the study showed a significant statistical differences in (psychological happiness, self-independence, environmental mastery, and self-acceptance , and psychological peace) depending on the situation variable the differences were in favor of non-orphans, also showed an existed effect of the predictive power of the psychological reassurance contribution to psychological happiness among orphaned and normal teenagers.

Also, a Study of Buczkym (2016) on the psychological happiness and its relationship with the life stressful events on university students, where the researcher used the psychological happiness scale and the scale of stressful life, and the results showed an inverse relationship between mental happiness and stressful life events among university students. As for Wiesdkhast et al. (2018), that aimed to find out the relationship between happiness and social adjustment in patients with Parkinson's disease, and the results of the study indicated a positive relationship between social adjustment and happiness among the sample members.

Gusniarti, et al. (2017) which aimed to investigate the relationship between happiness and adjustment social among the first year students of Indonesia and China, and a the results showed existence of a positive correlation between happiness and social adjustment, and showed existence of difference in results between groups from China and Indonesia , in addition to Kazim (2017) which aimed to investigate the relationship between psychological happiness and harmony psycho - social among students in the Faculty of Education, the results of the study showed the existence of a positive relationship between 
psychological happiness and harmony psychological and social, that respondents have a high level of psychological happiness and psychological adjustment .

Method

\section{Research Design}

This study used a quantitative approach to investigate the levels of happiness and psychosocial adjustment and its correlation between the variables among teenagers in the protection and care houses in Amman.

\section{Participants}

82 teenagers were chosen 41 Male and 41 Female residing in protection and care houses in Amman / Jordan, their age ranged between 16-12 Years.

\section{Data Collection tools}

Happiness scale

The researchers developed the happiness scale after reviewing the theoretical literature and previous studies, and some previous measures that were concerned with the subject of the study (Shawaqfeh \& Almahaireh, 2019; Medvedev, et al.; 2017, Almatarneh, 2015). And the scale is contained 20 items with five-Likert scale, and the discriminative significance values ranged between (0.30-0.75), and the test-retest value (0.81) while the internal consistency coefficient with the Cronbach-alpha (0.87).

The Psychosocial adjustment Scale

The researchers developed the scale after referring to the study of (Alkhawaldeh, 2018;
Alaloi, 2017; Barry, Briggs, \& Sidoti, 2019), And the scale is contained 38 items with five-Likert scale; included two dimensions: the psychological dimension and the social dimension, and the discriminatory significance values ranged between (0.30-0.78) and the test-retest value (0.83) A while the internal consistency coefficient with the Cronbach-alpha (0.92)

\section{Data Collection}

The researchers review the theoretical literature and previous studies, and determine the participants, developed the two scales, obtaining the approvals, and apply the study tools on the study sample within the age group (16-12 )in protection and care houses in Amman, finally extract findings and recommendations.

\section{Data analysis}

The researchers used SPSS to analyze the data. For the first and second questions, the average and standard deviations was calculated, while for the third question, the Pearson correlation coefficient was used, and finally for the fourth question the independent t-test was used.

\section{Findings}

The level of happiness among adolescents in protection and care houses in Amman

To answer this question, the means, and standard deviations of the responses of the participants were calculated, and the table 1 shows the

Table 1: The averages and standard deviations of the happiness scale

\begin{tabular}{lllll}
\hline N. & Item & mean & Std. Dev. & Value \\
\hline 1 & I see myself positively. & 4.14 & 1.00497 & High \\
& I have goals that I strive to achieve. & 3.88 & 1.00413 & High \\
2 & I feel the pleasure of being with others. & 3.87 & 0.859 & High \\
17 & I feel optimistic about the future. & 3.85 & 1.01492 & High \\
15 & I have fond memories of my life. & 3.76 & 1.13200 & High \\
\hline
\end{tabular}




\begin{tabular}{|c|c|c|c|c|}
\hline 10 & $\begin{array}{l}\text { I have the ability to please myself and others } \\
\text { with the simplest things. }\end{array}$ & 3.74 & 1.01832 & High \\
\hline 8 & I strive to develop my own skills. & 3.69 & 1.06468 & High \\
\hline 20 & I self-reinforce for every achievement. & 3.69 & 1.09892 & High \\
\hline 5 & I see that my health is good. & 3.68 & 1.21034 & Moderate \\
\hline 6 & $\begin{array}{l}\text { I feel like I have a lot of energy to help } \\
\text { others. }\end{array}$ & 3.70 & 1.12253 & Moderate \\
\hline 18 & I feel joy in my life. & 3.62 & 1.04036 & Moderate \\
\hline 16 & $\begin{array}{l}\text { I feel satisfied and happy about many } \\
\text { situations in my life. }\end{array}$ & 3.62 & 1.13568 & Moderate \\
\hline 13 & I have a good effect on life situations. & 3.61 & 1.07616 & Moderate \\
\hline 11 & I accept myself with all its faults. & 3.61 & 1.19364 & Moderate \\
\hline 9 & I feel that my appearance is attractive. & 3.57 & 1.13335 & Moderate \\
\hline 19 & I abide by what is being asked of me. & 3.50 & 1.11555 & Moderate \\
\hline 4 & I see life as good. & 3.36 & 1.15901 & Moderate \\
\hline 7 & Happy with who I am in the current situation. & 3.32 & 1.20310 & Moderate \\
\hline 3 & I wake up rested. & 3.23 & 1.21086 & Moderate \\
\hline 14 & I see that life is decent with me. & 3.22 & 1.07284 & Moderate \\
\hline & Happiness & 3.63 & 0.470 & Moderate \\
\hline
\end{tabular}

Table 1 shows that the mathematical averages of the responses to the happiness scale ranged between 3.23 and 4.14. The highestscoring item (I see myself positively) averaged 4.14, a high level, while the lowest-scoring item (I see that life is decent with me) averaged 3.23, a moderate level. The mean total happiness score was a moderate 3.63 , with a standard deviation 0.47 .

The averages and standard deviations showed that the happiness level of adolescents living in protective and caring houses was "moderate"

This can be explained by the fact that the level of happiness differs from one person to another, and it was different among teenagers between low, moderate, and high. as it was a result of the averages of all teenagers 'responses on the scale (moderate), and this is due to the existence of various programs and activities organized and unorganized. which tend to bring joy and pleasure to their hearts, and leads to feel comfort and harmony with the surroundings, and makes them look positively at themselves, and become optimism of the future, these programs are psychological discharge programs, sports activities, family communication through phone calls, vacations during school holidays and holidays, and meeting brothers among the centers, and there is also a program for those who do not have brothers or relatives so they can communicate by coordinating a meeting with those who brought them up or who they consider brothers in education in other protection houses, and to maintain good relations with sponsors, in addition to handicraft activities, recycling materials, Birthday parties, internal entertainment trips, external camps such as Aqaba camp and 
Wadi Rum, participation in sports clubs such as karate, football, swimming pools and cultural centers, and participation in religious and national events, noting that all activities are part of targeted plans prepared by psychologists in cooperation with the implementing team and these activities are followed by a teenager's evaluation of their effectiveness.

The concept of happiness and a positive outlook on life differs from one person to another and differs from time to time and is due to several reasons, including characteristics of the individual's personality, age and situation, teenagers in the protection and care houses need continuity of programs that enhance their concept of happiness in order to raise the level of happiness from moderate to high.

Study results differed with the study (Shawaqfeh \& Almahaireh, 2019) Which was on the students at the University of Jordan, where the level of happiness was high and the reason for the difference is in the group age. The university student is fully aware of his capabilities and capabilities and enjoys psychological stability, unlike the teenager who is characterized by psychological instability. Also, the study of (AlSuwafi,2019) showed the level of happiness among students of Al-Mudhaibi State School in Malaysia, and the students got a high level of happiness. The reason is that the school environment and family stability contribute to the students 'feeling of comfort, reassurance and a sense of happiness.

\section{level of Psychosocial Adjustment among} adolescents in the protection and care houses in Amman

The averages and standard deviations of the sample responses were calculated for the measure of psychosocial adjustment. Table 2 shows

the results.

Table 2: averages and standard deviations of psychosocial adjustment scale

\begin{tabular}{llll}
\hline \multicolumn{1}{c}{ Dimensions } & Mean & Std. Dev. & Value \\
\hline psychological adjustment dimension & 3.27 & 0.4137 & Moderate \\
social adjustment dimension & 3.55 & 0.525 & Moderate \\
Psychosocial adjustment Scale & 3.40 & 0.402 & Moderate \\
\hline
\end{tabular}

The mean for psychosocial adjustment was a moderate 3.40 , with a standard deviation of 0.402 . The highest-averaging dimension "social adjustment dimension" averaged 3.55, and the lowest-scoring dimension "psychological adjustment dimension" averaged 3.27.

Arithmetic averages and standard deviations showed that the level of Psychosocial Adjustment of adolescents residing in protective and caring houses was "medium."

Arithmetic averages and standard deviations showed that the level of Psychosocial Adjustment of teenagers residing in protective and caring houses was "moderate".
The result can be explained that the level of Psychosocial Adjustment of teenagers varies between low, medium and high, and that the total average response of teenagers on the scale was "moderate", which is due to the presence of interest in teenagers in protection and care houses by providing psychological counseling services, and get the help from the psychotherapy and social treatment specialists.as it enhance the positive personality of the teenager, understanding his needs, knowing his abilities, employing them in his life and solving the problems he faces, in addition a psychologist should be available to conduct group and individual counseling sessions and makes preparation and follow-up plans for the teen to enable him to feel stability and harmony 
with the new environment; And to set future goals and implement them within the capabilities available to him, and supported the programs by the Ministry of Social Development and organizations that concerned of childhood and adolescence, also the level of Psychosocial Adjustment varies from one individual to another based on the nature of his personality, his level of awareness, and the extent of his response to the programs Introduced to him and how he employ what he acquired in his life skills. Nevertheless, the "moderate" degree is a relative degree of a teenager's feeling of emotional stability and psychological and social adjustment, since this segment of society needs a higher level of Psychosocial Adjustment due to psychological and social shocks and fluctuations they are going through, due to the circumstances that necessitated their exclusion from their natural families and their living in an governed environment with Institutional , legal rules, instructions, and regulations, which expose them to traumas affect their psychological status, especially as it is one of the psychological features of the adolescence stage, psychological fluctuations and instability, and this requires programs to raise the level of Psychosocial Adjustment of teenagers residing in protection and care houses to prevent psychological relapses. Thus, the teenager will be able to fully integrate into society after he exit, and he will enjoy mental health and a positive outlook for the society, with no feelings of revenge.

The results of this study approve with the study of (Zeleeva, Bykova, \& Varbanova, 2016) in the results of their studies as moderate in the psychosocial Adjustment of the sample members. And this study results differs with the study of both (Lmoshi, 2019) as the results of the study were that working children got a low level, and the reason was attributed to the children not receiving psychological and social support services, in addition to the exposure of working children to abuse by employers and the deprivation of the child from his most basic rights of feeling security, love and affection. but the results of (Alqadery ,2013) study found that the orphan child does not feel psychologically adjustment, it is due to the lack of a supportive environment for the orphan child in addition to the small size of the sample where it consists only four (4) Children In addition the study is considered old, and at the present time the level of interest in care houses has become better.

\section{Relationship between happiness and psychosocial adjustment among adolescents in protection and care houses in Amman}

The Pearson correlation coefficient was used to detect relationships between the variables. Table 3 displays the results of this analysis.

Table 3: Pearson correlation values between happiness and psychosocial adjustment

\begin{tabular}{lll} 
variable & & Psychosocial Adjustment \\
\hline \multirow{2}{*}{ Happiness } & Pearson Correlation & $0.693 * *$ \\
& Sig. & 0.000 \\
\hline$* *$. Correlation is significant at the 0.01 level (2-tailed).
\end{tabular}

Table 3 shows a statistically significant correlation between happiness and psychosocial adjustment. This correlation indicates that the higher the level of happiness, the higher the levels of psychosocial adjustment in the individual. The coefficient of correlation was found between $(0.693,48 \%)$, and the value are statistically significant at an indication level $\alpha=0.05$.
This can be explained by the interconnectedness and complementarity between the psychological programs offered in the houses of protection and care, and the methods of dealing with teenagers, and how to implement the targeted plans, as the defect in the implementation negatively affects the results. The program is considered successful if it is applied by the work 
team in an organized and away from randomness, which contributes to improve the level of Psychosocial Adjustment and happiness for teenagers in the protection and care houses, a remarkable note is that during the past ten years an improvement has been observed in the level of services provided in the protection and care houses, and in the last four years, began a documenting the achievements role's through their participation in quality control programs, which require the care houses to prepare continuous plans and programs for residents of protection and care houses, and these plans should be linked with psychological programs and activities organized for the happiness of teenagers in protection and care houses. It should be suitable for the group age, developmental characteristics and to the individual's culture, in addition to the continuous evaluation of the needs of teenagers and the appropriateness of the activities and programs provided to them, in order to improve them at a level that the teenager feels psychosocial adjustment and happiness, one of the goals that the care houses seeks for the teenager is to enjoy emotional balance and stability
Psychological and the ability to use appropriate methods and skills to solve problems that he faces in his life, Thus, he can enjoy his life, be optimistic about the future and feel happy.

The results approved with the study of (Gusniarti. et al, 2017; shirali \& Golestanipour, 2017) Who discussed the psychological adjustment with happiness and the results of studies showed that there is a positive correlation between psychological and social harmony and happiness, the researchers explained this result that the higher the psychological and social level of adjustment level increased the happiness of the individual, and here our current study result is approved with the results of previous studies.

\section{differences in the level of Psychosocial} Adjustment and happiness according to brothers exist

The averages, standard deviations and independent $\mathrm{t}$-test were calculated for the Psychosocial Adjustment and happiness scores according to brothers exist. Table 4 displayed the result

Table 4: results of independent t-test to the study variables according to brothers exist

\begin{tabular}{|c|c|c|c|c|c|c|c|}
\hline Variable & brothers exist & N. & mean & Std. Dev. & $\mathbf{T}$ & DF & Sig. \\
\hline \multirow{2}{*}{ Psychological Adjustment } & Exist & 47 & 3.45 & 0.273 & \multirow{2}{*}{4.641} & \multirow{2}{*}{80} & \multirow{2}{*}{0.000} \\
\hline & Not exist & 35 & 3.10 & 0.405 & & & \\
\hline \multirow[t]{2}{*}{ Social Adjustment } & Exist & 47 & 3.85 & 0.430 & \multirow{2}{*}{4.745} & \multirow{2}{*}{80} & \multirow{2}{*}{0.000} \\
\hline & Not exist & 35 & 3.34 & 0.538 & & & \\
\hline \multirow[t]{2}{*}{ Happiness scale } & Exist & 47 & 3.86 & 0.435 & \multirow{2}{*}{3.280} & \multirow{2}{*}{80} & \multirow{2}{*}{0.002} \\
\hline & Not exist & 35 & 3.53 & 0.494 & & & \\
\hline
\end{tabular}

Table 4 indicates that there are statistically significant differences at the level of $(\alpha=0.05)$ in the levels of Psychosocial Adjustment and happiness according to the brothers exist variable, with the participants who has brothers scoring higher on means.

This can be explained as the proportion of their brothers in the protection and care houses are the largest category due to the increase in the number of disintegration categories of family and the presence of the brothers together give them the strength to some people to overcome the challenges together, this helps the elder brother to act the role of the father with his younger brother. and what the older brother acquires from the experiences he teaches to his brother, but the teenagers who do not have brothers they live in internal conflict because of their feelings of loneliness and dispersion that weaken their level of adjustment despite the availability of 
psychological and social supportive services. Thus, teenagers who do not have brothers need more psychological and social support than those who have brothers to raise their level of Psychosocial Adjustment. differences in the level of Psychosocial Adjustment and happiness according to the age

The averages, standard deviations and independent $\mathrm{t}$-test were calculated for the Psychosocial Adjustment and happiness scores according to age. Table 5 displayed the result.

Table 5: results of independent t-test analysis to the study variables according to the age

\begin{tabular}{llllllll}
\hline Variable & age & N. & mean & Std. Dev. & T & DF & Sig. \\
\hline Psychological Adjustment & less than 15 & 61 & 3.42 & 0.275 & \multirow{2}{*}{5.517} & \multirow{2}{*}{80} & \multirow{2}{*}{0.000} \\
& bigger 15 & 21 & 2.97 & 0.433 & & & \\
Social Adjustment & less than 15 & 61 & 3.77 & 0.464 & & \\
& bigger 15 & 21 & 3.24 & 0.557 & & 80 & 0.000 \\
Happiness scale & less than 15 & 61 & 3.82 & 0.471 & \multirow{2}{*}{3.473} & 80 & 0.001 \\
& bigger 15 & 21 & 3.42 & 0.417 & & & \\
\hline
\end{tabular}

Table 5 indicates that there are statistically significant differences at the level of $(\alpha=0.05)$ in the levels of Psychosocial Adjustment and happiness according to the age variable, with the aged less than 15 participants scoring higher on means.

This can be explained despite the fact that some previous studies show that older age groups among teenagers in natural conditions are more compatible than the younger age groups, but the averages of the results of measurements explained that teenagers in the protection and care houses less than 15 years old are more compatible ,this is due to the nature of the services in protection and care houses in Jordan, as the young age groups are within a controlled environment and have limited social relations, so the capabilities available to them within his capacity and needs so they are easy for him to adapt, but the older teenagers (more than 15 years old), they face greater challenges in society due to get out of the care houses and join the labor market or vocational training or learning in an academy to raise his level of knowledge, which requires a greater ability to deal with the external community within the culture of the community pressure on people who do not belong to independent natural families, and thus Programs should be prepared that help to raise the level of Psychosocial Adjustment of teenagers older than 15 years old in a way that contributes them to enjoy Adjustment and harmony with the external community and feel a sense of comfort and happiness.

\section{Conclusion}

The levels of happiness and Psychosocial Adjustment of adolescents residing in protection and care houses in Amman, range from low to high level, but the average adolescents 'responses on the two scales were (average), and this requires increasing programs that enhance the feeling of happiness and psychosocial adjustment among adolescents in order to raise Their level and the prevention of its decline, as the adolescence group is characterized by emotional instability, and the results of the study showed a positive relationship between the measures of happiness and psychosocial adjustment, and this indicates that feeling happy improves the level of Psychosocial Adjustment, and the results also showed that there are differences in the measures between adolescents who have brothers who have didn't have brothers, and there are differences according to age, and this call to consider in future studies of adolescents in the protection and care houses essential variables and the brothers exist and age.

\section{Limitations and future directions}

This study was conducted with a sample of undergraduate students enrolled in last quarter of the 2019 year, the study included all the role of the protection and care of the Ministry of Development of Social Volunteer and government in the city of Amman. The results of the study 
were interpreted from the participants' responses to the happiness scale and the psychosocial adjustment scale. The researchers recommend continuation of programs and studies geared towards teenagers living in the protection and care houses for the prevention of the happiness and psychosocial adjustment, and a comparison between adolescents in the role of the study Protection, care, and adolescents in foster families.

\section{References}

[1] Abdul Rahman, N. (2018). Behavioral and Affective Disorders and Psychosocial Adjustment, Academic Book Center for Publishing and Distribution.

[2] Alawi, A. (2017), Psychological flexibility and its relationship to Psychosocial Adjustment among students in Jordan, Unpublished master's thesis, Faculty of Educational Sciences, Amman Arab University: Jordan.

[3] Almatarneh, I. (2015). Psychological happiness and its relationship to social support and self-esteem among students of Mu'tah University, Unpublished master's thesis, Mutah University, Karak, Jordan.

[4] Al-Sawafi, M. (2019). Psychological happiness and its relationship to selfconcept among ninth grade students in the Wilayat of Al Mudhaibi in the Sultanate of Oman, Journal of Educational and Psychological Sciences, (10) 3, 3399-2522. http://search.shamaa.org/FullRecord?ID=24 8855 .

[5] Alsead, M. (2014), Environmental Quality and its Relationship to the Psychosocial adjustment of the Child, The Arab Bureau of Knowledge.

[6] Al-Shammari, F. (2017). Predicting happiness through psychological security of orphaned teenagers in care and ordinary centers, Unpublished master's thesis, Naif Arab University for Security Sciences: Saudi Arabia.
[7] Amalu, M. (2017). Family environment and self-esteem as predictors of psychological adjustment of secondary school students from divorced homes in cross river state, Nigeria. Journal of research \& method in education, 7(6), 9-16. https://www.semanticscholar.org/paper/Fa mily-Environment-and-Self-Esteem-as-

Predictors-ofAmalu/ce569b0eddebe615d05ae53d66b181 $5 \mathrm{de} 62 \mathrm{f} 23 \mathrm{a} 0$

[8] Amer, T. and Al-Masry, I. (2017). Care for orphans, Dar Al Uloom Publishing.

[9] Atwood, T., \& Schooler, J. (2014). The whole life adoption book: Realistic advice for building a healthy adoptive family. Tyndale House.

[10] Barry, C. T., Briggs, S. M., \& Sidoti, C. L. (2019). Adolescent and Parent Reports of Aggression and Victimization on Social Media: Associations With Psychosocial Adjustment. Journal of Child and Family Studies, 28(8),

2286-2296. https://doi.org/10.1007/s10826-019-014451

[11] Bazrafshan, M. R., Abdi, A., Masmouei, B., Kavi, E., Abshorshori, N., Akbari, L., ... \& Zakeri, M. (2018). The relation of social happiness and adjustment with vandalistic behaviour of the children and young adults in the families under supervision of welfare office. Journal of Clinical and Diagnostic Research, 12(8), Lc5-Lc9. https://doi.org/10.7860/Jcdr/2018/35184.11 916

[12] Beck, A. (2008). Cognitive Therapy Foundations and Dimensions, National Center for Translation.

[13] Bushkima, A. (2016). Psychological happiness and its relationship to stressful life events among university students: a field study at Medea University, psychological studies - Baseera Center for Research, 13,131-142. https://search.emarefa.net/detail/BIM806573 
[14] Dewi, A. K., Agustin, R. W., \& Satwika, P. A. (2017, August). The Relationship between Emotion Maturity and Social Adjustment with Migrant Employees' Psychological Well-being at PT. Pelabuhan Samudera Palaran Samarinda. In 8th International Conference of Asian Association of Indigenous and Cultural Psychology (ICAAIP 2017). Atlantis Press. https://doi.org/10.2991/icaaip-17.2018.18

[15] Friedman, C. P., \& Wyatt, J. (2005). Evaluation methods in biomedical informatics. Springer Science \& Business Media.

[16] Gusniarti, U. Rahaju, S. English, A. Dewi, A. \& Xin, J (2017). The relationship between happiness and social adjustment of Indonesian and Chinese students: A crosscultural study, Trends and Issues in Interdisciplinary Behavior and Social Science, Jogjakarta, Indonesia. https://doi.org/10.1201/9781315269184

[17] Herbert, M. (Ed.). (2016). Psychology for social workers. Springer.

[18] Kamali, T. P., Yazdkhasti, F., Oreyzi, H., \& Chitsaz, A. (2018). A Comparison of Effectiveness of Dohsa-hou and the Alexander Technique on Happiness, Social Adjustment, Hope, Mental Health, and Quality of Life in Patients with Parkinson's Disease. Japanese Psychological Research. https://doi.org/10.1111/jpr.12184

[19] Khalladi, Y. and Zagai, N. (2012). Early childhood and awareness of parental treatment style in relation to teenagers' psychosocial adjustment, Ibn Battuta for Publishing and Distribution.

[20] Khawaldeh, M. (2018). Internet addiction and its relationship to psychosocial adjustment among upper primary school students in Amman. Unpublished MA Thesis, Amman Arab University: Jordan.

[21] Khoj, H. (2014). A proposed scenario for developing methods of caring for orphans in Saudi Arabia in light of the trends of some Arab countries, "A Comparative
Study", Journal of Educational Sciences, (4) 22 , 440-381. http://search.shamaa.org/FullRecord?ID=11 0233.

[22] Licensing and Management System for Residential Child Care Houses No. (49) for a year (2009). The Official Journal. (4976), 4151.

$16 / 8 / 2009$

http://www.mosd.gov.jo/UI/Arabic/ShowC ontent.aspx ?ContentId=94

[23] Lmoshi, H. (2019), The Psychological and Social Compatibility of The Working Child, Center for Research and Development of Human Resources. (2) 2, 189-169.

https://search.mandumah.com/Record/9448 91

[24] Medvedev, O. N., Siegert, R. J., Mohamed, A. D., Shepherd, D., Landhuis, E., \& Krägeloh, C. U. (2017). The Oxford Happiness Questionnaire: transformation from an ordinal to an interval measure using Rasch analysis. Journal of Happiness Studies, 18(5),

1425-1443. https://doi.org/10.1007/s10902-016-9784-3

[25] Melgosa, J., \& Melgosa, A. D. (2010). Positive mind: A practical guide for any situation. Editorial Safeliz.

[26] Ministry of Social Development (2019). Brief on the protection and care houses and the annual statistical report, Directorate of Family and Protection, Department of Protection and Care Houses, Amman: Jordan.

[27] Mohammadzadeh, M., Awang, H., Shahar, H. K., \& Ismail, S. (2018). Emotional health and self-esteem among adolescents in Malaysian orphanages. Community mental health journal,54(1), 117-125. https://doi.org/10.1007/s10597-017-0128-5

[28] Potrus, H. (2008). Adjustment and child mental health, March House for Publishing and Distribution.

[29] Qadri, h. (2013), Psychosocial adjustment of the orphan child, Journal of Studies in Childhood - Baseera Center for Research, 
Consultation and Educational Services.

4,129-156.

https://search.emarefa.net/detail/BIM519210.

[30] Rizvi, A. H. (2016). Combining Marriage and Career: The Professional Adjustment of Marital Teachers. Journal of Education and Practice, 7(7), 140-143. http://iiste.org/Journals/index.php/JEP

[31] Seligman, M. E. (2004). Authentic happiness: Using the new positive psychology to realize your potential for lasting fulfillment. Simon and Schuster.

[32] Shawaqfeh, B., \& Almahaireh, A. (2019). Techno Wellness and Its Relationship with Happiness and Optimism Among University of Jordan Students. Journal of Social Studies Education Research, 10 (2), 167-145. https://www.learntechlib.org/p/216598/.

[33] shopr, M. (2017), Adolescence between the gender, Dar Safa.

[34] Shulga, T. I., Savchenko, D. D., \& Filinkova, E. B. (2016). Psychological Characteristics of Adolescents Orphans with Different Experience of Living in a Family. International journal of environmental and science education, 11(17), 10493-10504. http://www.ijese.net/makale/1371.html

[35] Snell, R. S. (2000). Studying moral ethos using an adapted Kohlbergian model.
Organization studies, 21(1), 267-295. https://doi.org/10.1177/0170840600211006

[36] Speier, AH, Nordboe, D., Farberow, NL (2015). Psychosocial issues for children and teenagers in disasters. US Department of Health and Human Services Substance Abuse and Mental Health Services Administration Center for Mental Health Services.

[37] White, Nicholas (2013). Happiness Historical Brief, Knowledge World Series, (405).

[38] Williams, P. G., Holmbeck, G. N., \& Greenley, R. N. (2002). Adolescent health psychology. Journal of consulting and clinical psychology, 70(3), 828. https://doi.org/10.1037/0022006X.70.3.828

[39] Zahraa, F. (2017). Happiness theory, Molhimon for Publishing and Distribution.

[40] Zahran, H. (2002). Studies in mental health and psychological counseling, Books World.

[41] Zeleeva, V. P., Bykova, S. S., \& Varbanova, S. (2016). Psychological and Pedagogical Support for Students' Adaptation to Learning Activity in High Science School. International Journal of Environmental and Science Education, 11(3), 151-161. http://dx.doi.org/10.12973/ijese.2016.299a 